\title{
Caracterização morfométrica da península Fildes, Ilha Rei George, Antártica Marítima
}

\author{
André Medeiros de Andrade*, Roberto Ferreira Machado Michel ${ }^{* *}$, Ulisses Franz Bremer ${ }^{* * *} \&$ \\ Carlos Ernesto G. R. Schaefer ${ }^{* * *}$ \\ *Professor da Universidade Federal dos Vales do Jequitinhonha e Mucuri, Instituto de Ciências Agrárias, Campus Unaí. E-mail: \\ andre.medeiros@ufvjm.edu.br. \\ ** Professor da Universidade Estadual de Santa Cruz, Dep. de Ciências Agrárias e Ambientais. \\ ${ }^{* * *}$ Professor da Universidade Federal do Rio Grande do Sul, Instituto de Geociências. \\ ${ }^{* * * *}$ Professor da Universidade Federal de Viçosa, Departamento de Solos.
}

Recebido em 12/2016. Aceito para publicação em 02/2017. Versão online publicada em 06/2018 (http://seer.ufrgs.br/paraonde)

\begin{abstract}
Resumo: Na região da Antártica Marítima, apesar das severas condições climáticas, há vegetação, hidrografia e feições geomorfológicas que configuram os ecossistemas locais. Este trabalho tem como objetivo quantificar e analisar os parâmetros morfométricos da Península Fildes, localizada na Ilha Rei George, Antártica Marítima. 0 modelo digital do terreno (MDT) foi gerado a partir dos dados altimétricos da carta topográfica da Península Fildes e, a partir do MDT, foram gerados os produtos de hipsometria, declividade, orientação das vertentes e forma do terreno. A partir desses produtos foi possível analisar a morfometria da Península Fildes e, posteriormente, quantificar a relação entre os produtos morfométricos e a geomorfologia local. Os resultados obtidos apontam que a altimetria média da Península Fildes é de 58,73 m, com predominância de relevo ondulado e suave ondulado. As vertentes orientadas para oeste possuem a maior representatividade, e não houve uma classe de forma do terreno com área destacadamente superior às outras. Os resultados desse estudo demonstram que os produtos morfométricos podem ser utilizados para fins de análise das variáveis que compõem o relevo dos ambientes da Antártica Marítima. Esse estudo contribui para ampliar as informações de ambientes antárticos obtidos com escalas detalhadas.
\end{abstract}

Palavras-chave: Geoprocessamento, Análise Morfométrica, Modelo Digital do Terreno.

\section{Morphometric characterization of the Fildes peninsula, King George Island, Maritime Antarctica}

\begin{abstract}
In the Antarctic Maritime region, despite the severe climatic conditions, there is vegetation, hydrography and geomorphological features that configure the local ecosystems. The aim of this work is to analyze the morphometric parameters of the Fildes Peninsula, located on King George Island, Antarctica Maritime. The digital terrain model (DTM) was generated by the altimetric data of the topographic map of the Fildes Peninsula. From these DTM we derived Hypsometric, slope, aspect and terrain shape index. We quantify the morphometry and relate to the geomorphological features of the Fildes Peninsula. The relationship between morphometric data and local geomorphology was also quantified. The results show that the average altimetry of the Fildes Peninsula is $58.73 \mathrm{~m}$, with predominance of undulating and gently undulating reliefs. The west-oriented aspect have the largest area, and there is no terrain shape class with an area markedly superior to the others. The results of this study show that morphometric products can be used to analyze the elements that configure the relief of environments in the Antarctic Maritime. This study expands information on Antarctic environments obtained with detailed scales.
\end{abstract}

Keywords: Geoprocessing, Morphometric Analysis, Digital Terrain Model.

\section{Caracterización morfométrica de la península Fildes, Isla Rey George, Antártida Marítima}

\footnotetext{
Resumen: Los cambios ambientales, especialmente los que ocurren en la criosfera, pueden resultar en consecuencias a nivel local, regional y global. Aunque em la región de la Antártida Marítima ocurre condiciones meteorológicas severas, su ecosistema tiene vegetación, hidrografía y diversas características geomorfológicas. Este estudio pretende cuantificar y analizar los parámetros morfométricos de la península Fildes, situado en la isla Rey Jorge, Antártida marítima. El modelo digital del terreno (MDT) fue creado a partir de datos de altimetría de la carta topográfica de la Península Fildes, y desde el MDT se generaron hipsometría, declividad, orientación de la superfície y la forma del terreno. A partir de estos productos ha sido posible analizar la mor-
} 
fometría de la península Fildes juntamente con las características geomorfológicas, para cuantificar la relación entre la morfometría y la geomorfología local. Los resultados muestran que la altimetría medio en Peninsula Fildes es 58,73 m. Las superficies orientadas hacia el oeste son la mayoría y no ocurre una clase de forma del terreno con superficie notablemente superior. Este estudio se ha ganado importancia debido a la escasez de estudios de los ambientes antárticos en escalas detalladas. Los productos morfométricos pueden ser utilizados para analizar el ambiente de la Antártida Marítima.

Palabras-Clave: Geoprocesamiento, Morfometría, Antártida Marítima.

\section{Introdução}

A criosfera é o ambiente com presença de neve, gelo, geleiras e permafrost (FRENCH, 2007), e tem intensa influência no clima local e global. Fatores como cobertura de neve e de vegetação, configuração do relevo, orientação da vertente e presença de corpos d'água também interferem na dinâmica dos ecossistemas da criosfera (FRENCH, 2007). Destaca-se ainda que em toda a região antártica, menos de $1 \%$ de sua área é composta por superfícies livres de gelo, e da área total livre de gelo, aproximadamente 14\% está situada na Península Antártica e em suas ilhas (BOCKHEIM e HALL, 2002).

Estudos ambientais por meio de mapeamentos podem ser elaborados por meio da abordagem individual dos elementos que compõem o ambiente. Contudo, na superfície terrestre coexistem elementos como a vegetação, hidrografia e feições geomorfológicas, que constituem o ambiente, possuem inter-relação e para melhor compreensão é adequado o desenvolvimento de análises conjuntas, incluindo a abordagem morfométrica. Análises conjuntas viabilizam o monitoramento de variações no ambiente, além de auxiliar na gestão do uso e ocupação da superfície terrestre (COOPER E MURRAY, 1992).

Estudos morfométricos dos ambientes antárticos em escalas detalhadas são escassos, principalmente em decorrência da dificuldade em se realizar levantamentos em campo. Em compensação, técnicas de sensoriamento remoto e de geoprocessamento têm sido fundamentais para estudos que buscam a compreensão de ambientes periglaciais (GROSSE et al., 2005; ARIGONYNETO et al., 2007; ANDRADE et al. 2015; POELKING et al. 2015). A partir de modelos digitais do terreno é possível extrair produtos como hipsometria, declividade, orientação das vertentes e forma do terreno (MOORE et al. 1991). Esses produtos podem ser analisados utilizando técnicas de análises matriciais, possibilitado a melhor compreensão dos ambientes glaciais (NAPIERALSKI et al. 2007), além de auxiliar na interpretação de processos atuantes em um determinado ambiente (ETZELMÜLLER e SULEBAK, 2000; MENDES JUNIOR et al. 2010; ROSA et al. 2014).

Esse trabalho tem como objetivo quantificar e analisar parâmetros morfométricos da Península Fildes, localizada na Ilha Rei George, Antártica Marítima utilizando técnicas de geoprocessamento.

\section{2. Área de Estudo}

A Península Fildes está localizada na porção sudoeste da Ilha Rei George, fazendo parte do arquipélago das Ilhas Shetland do Sul, entre as latitudes $62^{\circ} 08^{\prime}$ e $62^{\circ} 14^{\prime}$ Sul e longitudes $59^{\circ} 02^{\prime}$ e $58^{\circ} 51^{\prime}$ Oeste (Figura 1). Na Ilha Rei George, o processo de deglaciação no holoceno teve início há aproximadamente 6000 anos, tendo ocorrido um ótimo climático entre 4.000 e 3.000 anos ap (BJÖRCK et al. 1991; YOON et al. 2000). A ilha possui a maior área do arquipélago, com aproximadamente 140.000 ha e a Península Fildes possui área de aproximadamente 2.900 ha, configurando-se na maior área livre de gelo da ilha (MICHEL et al, 2014).

A Península Fildes possui, em sua área livre de

Figura 1: Localização geral da região de estudo (a, b), da Ilha Rei George (c) e destaque para a Península Fildes (d).

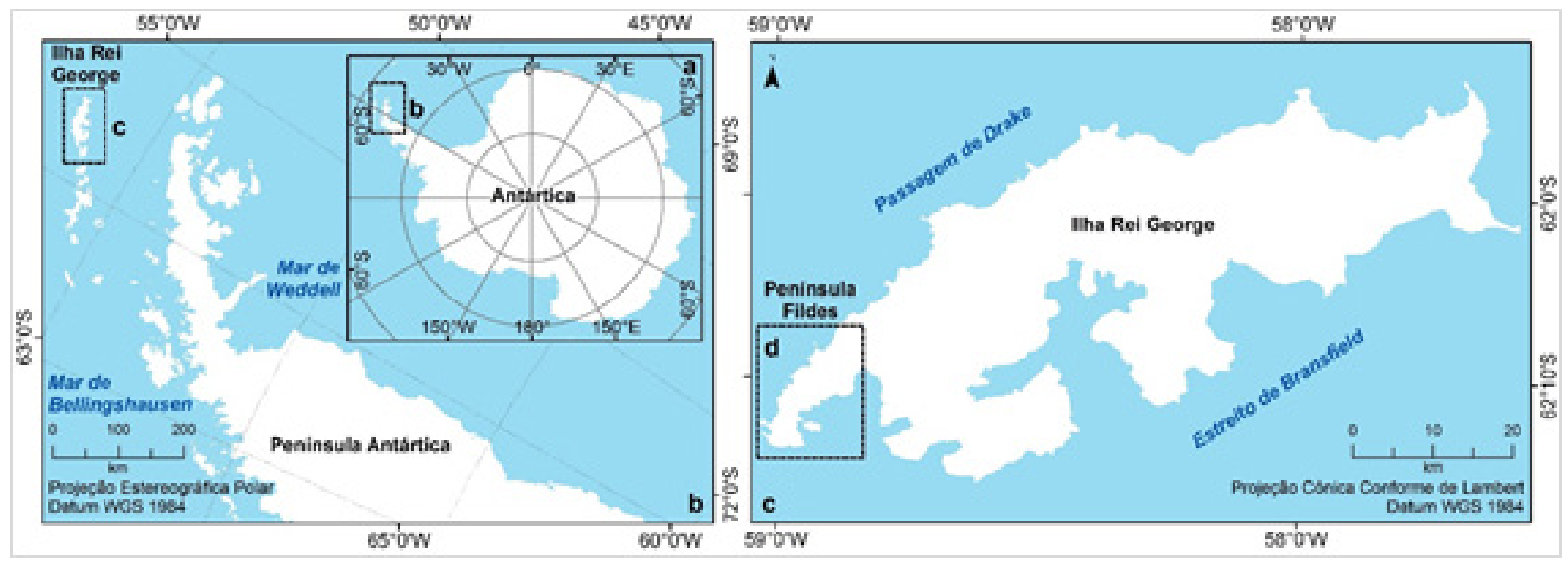

Fonte: André Medeiros de Andrade 
gelo, diferentes características ambientais. 0 processo de retração da geleira Collins resultou em áreas livres de gelo, com uma transição de áreas mais antigas, originárias no início do recuo das geleiras, até os ambientes proglaciais circunvizinhos à geleira Collins, resultantes do recente recuo da geleira. Segundo Michel (2014), nas áreas mais antigas ocorre predomínio de processos geomorfológicos periglaciais de solifluxão, crioturbação e nivação.

O relevo da Península Fildes éfortemente influenciado por processos paraglaciais e periglaciais (MICHEL et al. 2014). Os processos paraglaciais, que ocorrem de forma independente à presença de gelo, concentramse nas áreas livres de gelo na porção norte da península. Uma característica dessa área é a presença de morainas recentes, posicionadas próximas à borda frontal da geleira Collins. As feições periglaciais ocorrem em 70\% das áreas livres de gelo da Península Fildes, sendo

a superfície restante composta por formações estruturais e afloramentos rochosos oriundos de erosão glacial (MICHEL et al. 2014). Dentre as feições periglaciais, há predomínio de solos estruturados com padrão poligonal (LÓPES-MARTÍNEZ et al.2012), ocorrendo predominantemente nas plataformas soerguidas, com altimetria variando entre 30 e 100 m a.n.m., em relevo plano, associado à deficiência na drenagem e acúmulo de água dos processos de ablação (MICHEL et al. 2014). Outros elementos importantes no relevo da Península

Fildes são as plataformas marinhas soer- guidas, compostas principalmente por plataformas médias

(40-60 m a.n.m.) e plataformas superiores (90 m a.n.m.). Essas plataformas são caracterizadas por colinas planas e por possuírem seus limites principalmente em falésias ou praias (MICHEL et al. 2014).

Mesmo havendo incipiente pedogênese, o solo na área livre de gelo da Península Fildes possui relativo grau de desenvolvimento, principalmente se comparado aos padrões pedogenéticos de outros locais da Antártica (MICHEL, 2011). Ocorre predomínio de criossolos crioturbados nas áreas das plataformas, depósitos glaciais e bacias de drenagem, e concentração de processos de solifluxão em superfícies com declividades superiores a $11^{\circ}$, valor equivalente a $24,4 \%$ (MICHEL et al. 2014). A vegetação presente na Península Fildes é semelhante à encontrada em outras áreas livres de gelo nas Shetlands, incluindo musgo (Warnstorfia e $\mathrm{Sa}$ nionia sp.), líquen (Himantormia sp. e Usnea sp.) e cobertura mista de gramíneas (Deschamspia antarctica) (LINDSAY, 1971, PETER et al. 2008).

O clima da Península Fildes é do tipo marítimo sub-antártico, com ventos fortes, constantes variações meteorológicas e temperaturas mais amenas, com a temperatura média anual do ar de $-2^{\circ} \mathrm{C}$ e temperatura média do ar durante o verão podendo ser ligeiramente superior a $0^{\circ} \mathrm{C}$ (WEN et al., 1994). A precipitação pluvial varia entre 350 e $500 \mathrm{~mm}$ durante o ano, com concentração no verão (ØVSTEDAL e SMITH, 2001).

\section{Metodologia}

0 modelo digital do terreno (MDT) foi gerado a partir dos dados altimétricos da Península Fildes (IGM e INACH, 1996). As curvas de nível possuem equidistância de $5 \mathrm{~m}$ e foram geradas tendo o nível médio do mar como datum altimétrico de referência. Foi utilizado o interpolador topo to raster baseado no método Locally Adaptive Gridding proposto por Hutchinson (1989). Esse método de interpolação foi escolhido por utilizar um modelo que considera as características locais de drenagem, as linhas de fluxo e a grade de pontos cotados. No processo de interpolação dos dados altimétricos, o algoritmo generalizou a superfície a partir dos valores dos pontos cotados, e posteriormente utilizou as informações altimétricas para modelar as formas tridimensionais do terreno. 0 tamanho das células do MDT é de $1 \mathrm{~m}$, e a partir do MDT foram gerados outros produtos para análise da morfometria do relevo, tais como: hipsometria, declividade, orientação das vertentes e forma do terreno.

A altimetria foi representada através do mapa hipsométrico, a partir da segmentação do MDT em 10 classes, tendo cada classe a amplitude de $20 \mathrm{~m}$. Essa representação fornecerá as informações altimétricas da Península Fildes.

O cálculo da declividade do terreno foi feito através do cálculo da alteração máxima na elevação em uma determinada distância. Esse cálculo foi executado a partir de janelas móveis compostas por 8 células, que avaliam a inclinação e o vetor direcional da inclinação para cada célula que compõe o MDT. 0 mapa de declividade foi composto por seis classes temáticas, que abrangem os intervalos de declividade que descrevem as características do relevo (EMBRAPA, 1979; FRANCELINO et al. 2004; MENDES JUNIOR et al. 2010).

O mapa de orientação das vertentes foi elaborado com oito classes, definidas a partir dos ângulos azimutais da orientação de cada vertente (BURROUGH e MCDONNELL, 2011). Cada classe de orientação indica a direção cardeal de inclinação de uma determinada vertente.

A forma do terreno possibilita estimar os padrões de transporte, velocidade e intensidade de fluxos superficiais em uma superfície (DIKAU, 1990). Utilizando o método proposto por Moore et al. (1991) foram interseccionadas as curvaturas horizontais (convergente, divergente e planar) e as curvaturas verticais (côncava, convexa e retilínea), resultando em nove classes de forma do terreno.

Após a elaboração dos dados morfométricos, foram quantificadas as áreas absolutas e relativas de cada classe dos mapas hipsométrico, declividade, orientação das vertentes e forma do relevo.

Por fim, utilizou-se a ferramenta de calculadora de arquivos matriciais para executar a intersecção entre os dados morfométricos gerados e os dados de geomorfologia extraídos de Lópes-Martínez et al. (2012). 
As feições geomorfológicas foram georreferenciadas e digitalizadas, possibilitando analisar quantitativamente a relação entre as feições geomorfológicas e os dados morfométricos.

\section{Resultados e discussão}

A área livre de gelo da Península Fildes é de aproximadamente $2.984,2$ ha e a área da geleira Collins abrangida nesse estudo possui 416,9 ha. A partir de dados extraídos do MDT (Figura 2), constata-se que a altimetria média na península é de 58,73 $\mathrm{m} \pm 40,93 \mathrm{~m}$. Entretanto, desconsiderando a geleira Collins, a altimetria média da área livre de gelo é reduzida para 48,26 m $\pm 30,48 \mathrm{~m}$. Essa diferença deve-se à geleira Collins possuir os pontos mais elevados da península, com cotas variando entre 60 m e 190,66 m, enquanto na área livre de gelo, os pontos mais elevados, localizados nos terraços soerguidos, possuem 165,67 $\mathrm{m}$ de altitude, uma diferença de $25 \mathrm{~m}$ entre as altitudes máximas. As elevações predominantes estão concentradas entre 0 e $60 \mathrm{~m}$, englobando $65,1 \%$ de toda área livre de gelo (Tabela 1 ).

As duas classes geomorfológicas apresentadas por Lópes-Martínez et al. (2012) predominantes são as plataformas marinhas soerguidas e os solos padronizados, com áreas de aproximadamente 609,43 ha e 595,53 ha respectivamente. As plataformas marinhas soerguidas estão localizadas predominantemente entre $20-40 \mathrm{~m}(42,5 \%)$ e $40-60 \mathrm{~m}(37,1 \%)$. Os solos padronizados apresentam predomínio nos mesmos intervalos de elevação, porém, com predomínio entre 40-60 m $(40,8 \%)$ seguido de $20-40$ m $(24,7 \%)$. 0 padrão de localização dos solos padronizados está de acordo com o proposto por Lópes-Martínez et al. (2012).

Figura 2: Mapa hipsométrico da Península Fildes derivado do MDT.

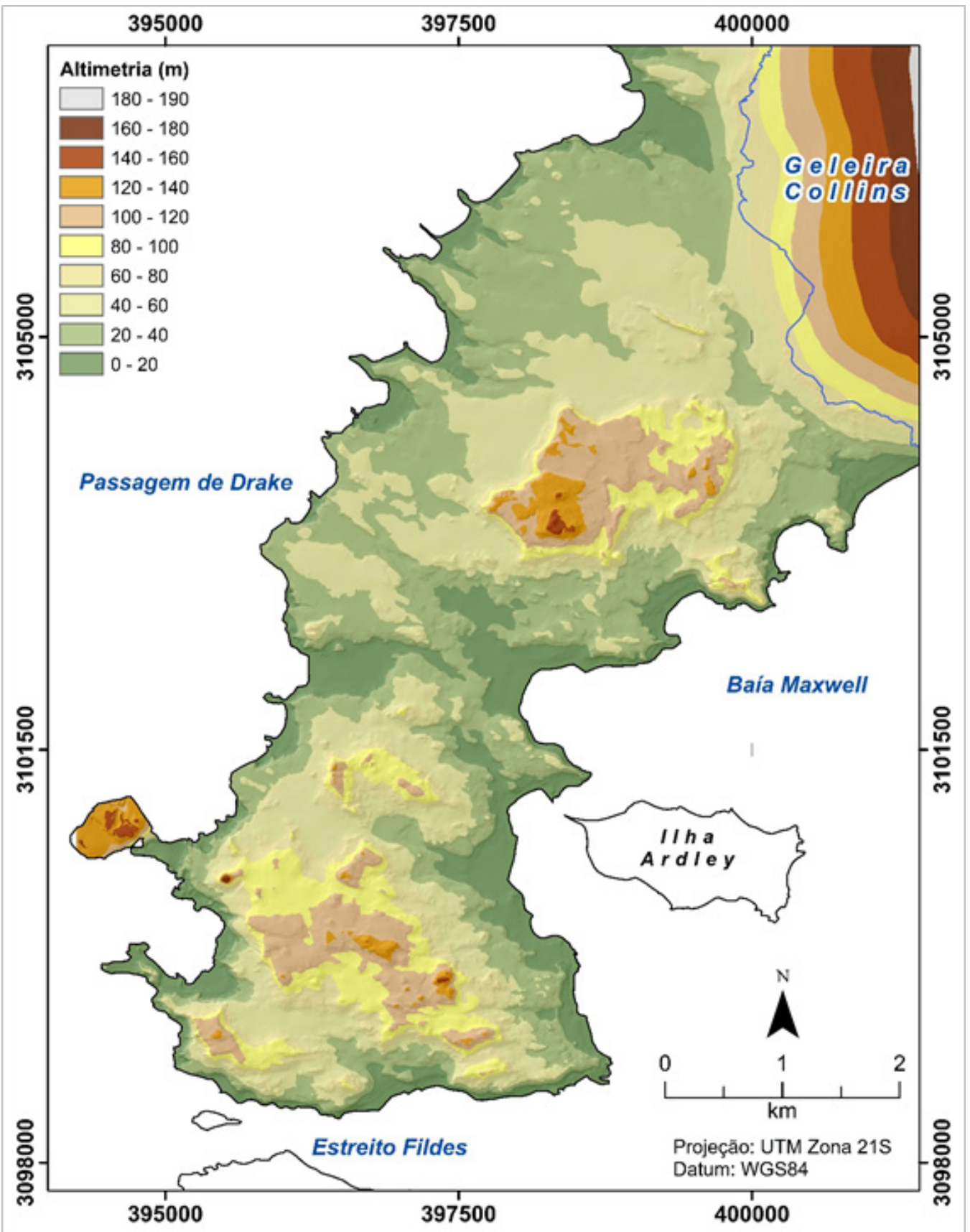

Fonte: André Medeiros de Andrade 


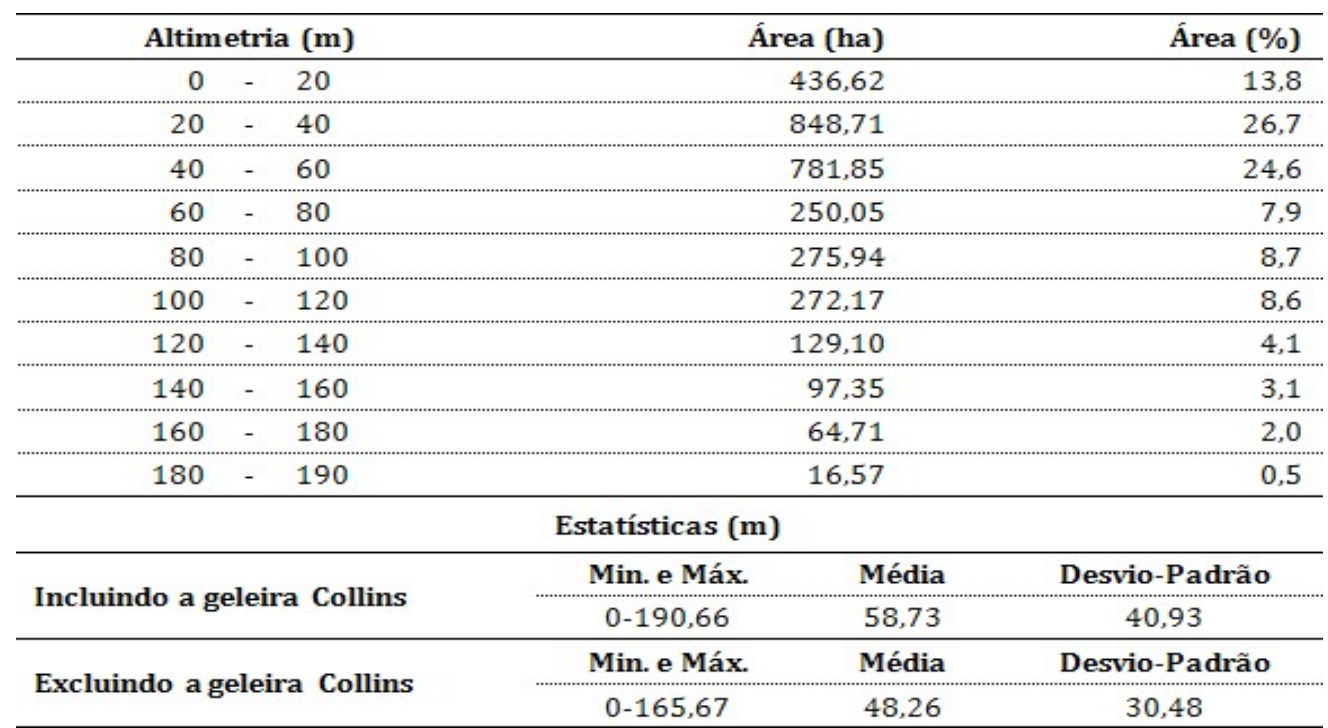

Fonte: André Medeiros de Andrade

Os relevos predominantes na Península Fildes são do tipo ondulado e suave ondulado, com declividades variando entre 8 e $20 \%$ e 3 e $8 \%$ respectivamente (Tabela 2). Juntas, as duas classes abrangem 1.982,12 ha, equivalente a $62,5 \%$ da área total. Na península existem poucas superfícies com declividades acentuadas, com os relevos classificados como montanhosos ou escarpados localizadas principalmente nas encostas

Tabela 2: Áreas absolutas, relativas e estatísticas das classes de declividade da Península Fildes.

\begin{tabular}{|c|c|c|c|}
\hline Relevo & Intervalo de declividade (\%) & Área (ha) & Área (\%) \\
\hline Plano & $0-3$ & 502,56 & 15,8 \\
\hline Suave ondulado & $3-8$ & 956,12 & 30,1 \\
\hline Ondulado & $8-20$ & 1026,00 & 32,3 \\
\hline Forte ondulado & $20-45$ & 477,49 & 15,0 \\
\hline Montanhoso & $45-75$ & 140,45 & 4,4 \\
\hline Escarpado & $>75$ & 70,45 & 2,2 \\
\hline \multicolumn{4}{|c|}{ Estatísticas (\%) } \\
\hline Min. e Máx. & Média & \multicolumn{2}{|c|}{ Desvio-Padrão } \\
\hline $0-518,57$ & 15,35 & \multicolumn{2}{|c|}{20,26} \\
\hline
\end{tabular}

Fonte: André Medeiros de Andrade

das plataformas soerguidas, como é o caso da meseta norte, que possui escarpas com $80 \mathrm{~m}$ de altura. 0 relevo na geleira Collins é constituído em 50,7\% suave ondulado e 48,9\% ondulado. Ainda ocorre $0,1 \%$ de relevo plano e $0,2 \%$ forte ondulado, localizados na extremidade frontal da geleira. A declividade média da geleira Collins é de $8,45 \%$ e o desvio padrão $2,81 \%$, indicando um padrão de ligeira ascendência na declividade ealtimetria (Figura 3).
As plataformas marinhas soerguidas e os solos padronizados estão localizados principalmente em relevos plano, suave ondulado ou ondulado, envolvendo respectivamente $80,2 \%$ e $77,2 \%$ da área compreendida por essas classes geomorfológicas. Deve-se destacar, que os solos padronizados também possuem 17,6\% de sua cobertura localizada em relevos forte ondulados, com declividades variando entre 20 e 45\%. Nas superfícies mais declivosas, a ocorrência dessas duas classes geomorfológicas é inexpressiva. 


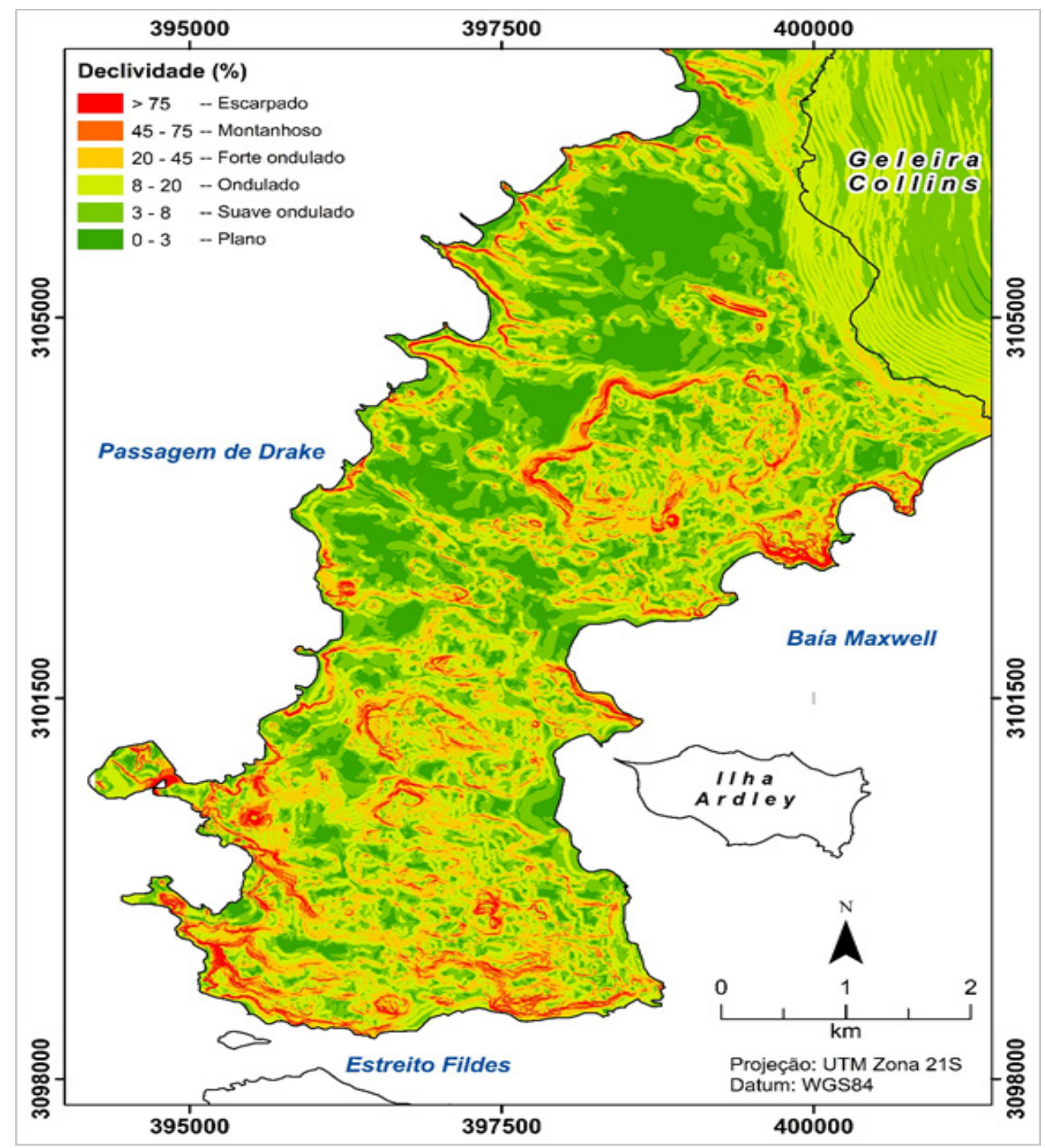

Fonte: André Medeiros de Andrade

O relevo da Península Fildes apresenta predomínio de vertentes orientadas para oeste $(20,2 \%)$, seguido por orientações direcionadas a sudoeste $(14,6 \%)$, norte $(13,2 \%)$, sul $(13 \%)$ e nordeste $(12,2 \%)$ (Tabela $3)$. As demais orientações apresentam individualmente menos de $10 \%$ da área total. Contudo, a prevalência de vertentes orientadas para oeste é decorrente do formato da geleira Collins, que possui $74 \%$ de suas vertentes orientadas para essa direção. Quando se avalia a orientação das vertentes somente das áreas livres degelo,

Tabela 3: Áreas absolutas e relativas das classes de orientação das vertentes da Península Fildes.

\begin{tabular}{lccr}
\hline \multicolumn{1}{c}{ Orientação da Vertente } & Ângulo Azimutal & Área (ha) & Área (\%) \\
\hline Norte & $337,5-22,5$ & 417,92 & 13,2 \\
\hline Nordeste & $22,5-67,5$ & 387,49 & 12,2 \\
\hline Leste & $67,5-112,5$ & 293,46 & 9,2 \\
Sudeste & $112,5-157,5$ & 272,75 & 8,6 \\
Sul & $157,5-202,5$ & 411,78 & 13,0 \\
Sudoeste & $202,5-247,5$ & 463,67 & 14,6 \\
Oeste & $247,5-292,5$ & 639,82 & 20,2 \\
\hline Noroeste & $292,5-337,5$ & 286,17 & 9,0 \\
\hline
\end{tabular}


a área das vertentes orientadas para oeste é reduzida para 331,38 ha, equivalente a $12 \%$ da área livre de gelo total. Elementos como a direção do vento, exposição à radiação solar e efeitos marítimos, são fatores rela- cionados diretamente à orientação da vertente, sendo, portanto, esse atributo fundamental na dinâmica dos ecossistemas da Antártica Marítima (Figura 4).

As vertentes das plataformas marinhas soergui-

Figura 4: Mapa de orientação das vertentes da Península Fildes derivado do MDT.

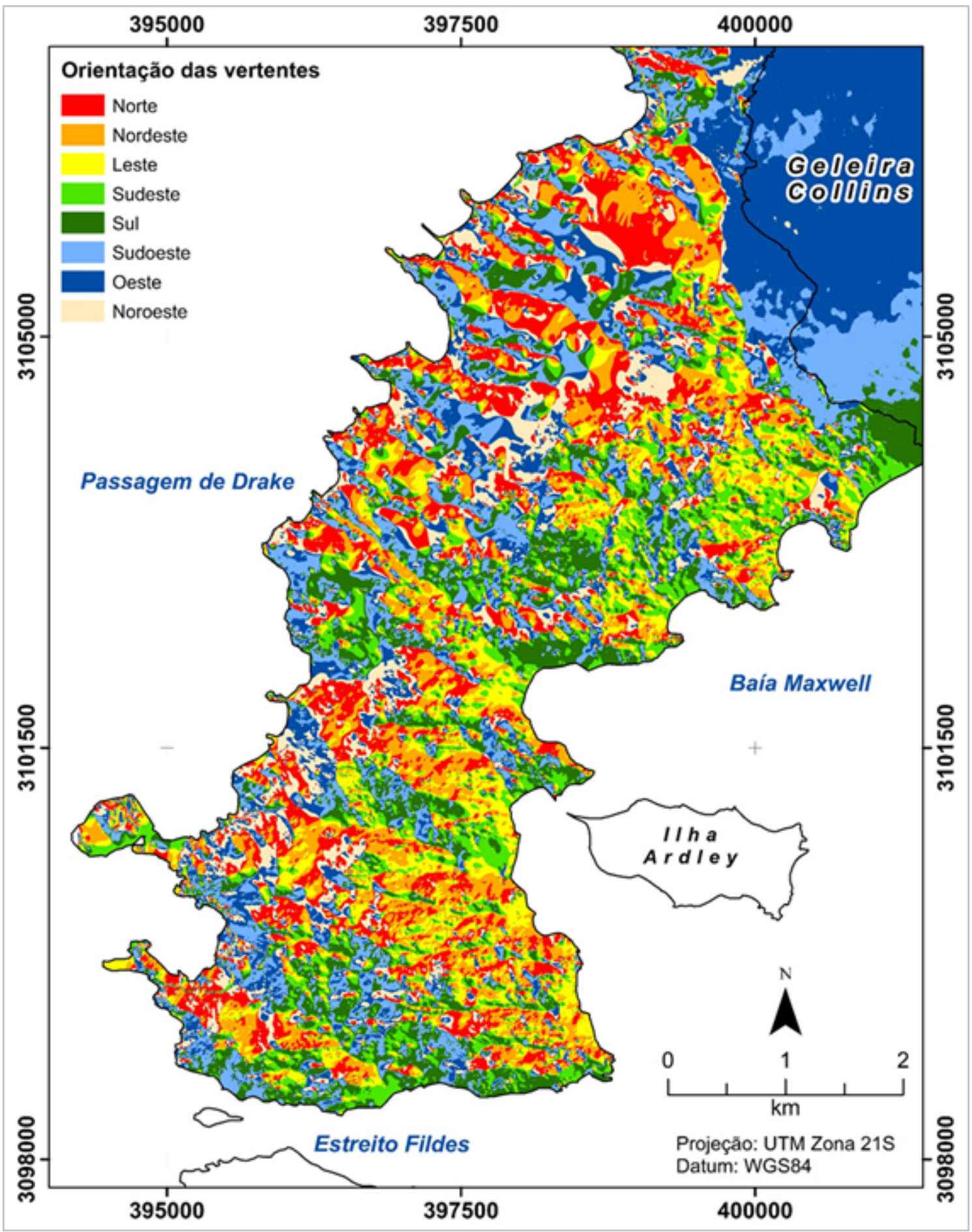

Fonte: André Medeiros de Andrade

das possuem predomínio na orientação para norte $(19,8 \%)$, sudoeste $(16,7 \%)$ e sul $(15,6 \%)$, englobando $52,1 \%$ de sua área total. Os solos padronizados apontam predomínio de orientação para nordeste 17,5\%) e norte $(17,2 \%)$, enquanto nas das demais vertentes, ocorre equilíbrio nos sentidos de orientação.

Na Península Fildes, não há uma classe de forma do terreno com área destacadamente superior (Tabela
4). As formas do terreno que possuem as maiores representatividades são: convergente e convexo $(20,6 \%)$, divergente e côncavo $(17,9 \%)$, divergente e convexo $(15,9 \%)$ e planar e convexo $(15,1 \%)$. Essas quatro classes somadas, contém 2.203,4 ha, equivalente a $69,4 \%$ da área total (Figura 5). A forma do terreno influencia os padrões superficiais de escoamento, sendo que os formatos convergentes e côncavos propiciam a 
Tabela 4: Áreas absolutas e relativas das classes de forma do terreno da Península Fildes.

\begin{tabular}{|c|c|c|}
\hline Forma do Terreno & Área (ha) & Área (\%) \\
\hline Convergente e Côncavo & 408,1 & 12,9 \\
\hline Convergente e Convexo & 653,9 & 20,6 \\
\hline Convergente e Retílineo & 31,2 & 1,0 \\
\hline Divergente e Côncavo & 566,9 & 17,9 \\
\hline Divergente e Convexo & 504,3 & 15,9 \\
\hline Divergente e Retílineo & 25,2 & 0,8 \\
\hline Planar e Côncavo & 367,7 & 11,6 \\
\hline Planare Convexo & 478,3 & 15,1 \\
\hline Planar e Retílineo & 137,4 & 4,3 \\
\hline
\end{tabular}

Fonte: André Medeiros de Andrade

Figura 5: Mapa da forma do terreno da Península Fildes derivado do MDT.

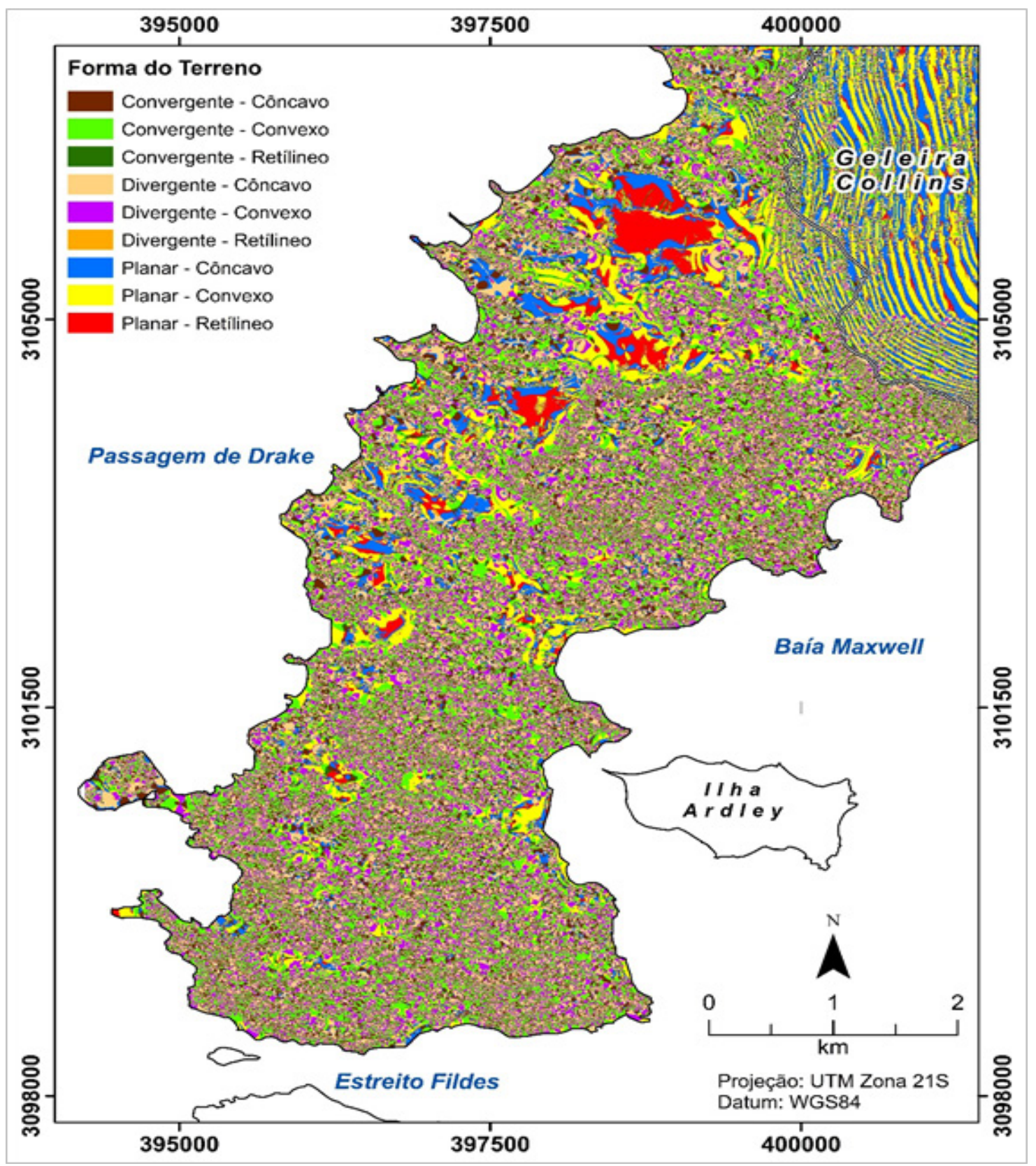

Fonte: André Medeiros de Andrade 
acumulação e concentração de materiais drenados, enquanto as superfícies divergentes e convexas facilitam a dispersão dos materiais drenados.

As formas do terreno que prevalecem nas plataformas marinhas soerguidas são as convergentes e convexas e as divergentes e côncavas, perfazendo respectivamente $17,4 \%$ e $17,3 \%$ da área total dessa feição geomorfológica. Também ocorrem as formas planar e convexo, planar e côncavo e divergente e convexo, cada uma totalizando $14 \%$ da área total das plataformas marinhas soerguidas. Nas áreas com solos padronizados, há prevalência nas formas do terreno convergente e convexo $(22,2 \%)$, divergente e côncavo $(19,4 \%)$ e divergente e convexo $(18,2 \%)$. Nas duas classes geomorfológicas, as formas do terreno com menores ocorrências são as do tipo convergente e retilíneoe divergente retilíneo, com aproximadamente 1\% das áreas totais.

Apesar de as penínsulas da Ilha Rei George aparentar visualmente alto grau de similaridade geomorfológica, ao comparar os dados morfométricos da

Penínnsula Fildes com os dados da Península Keller (MENDES JUNIOR et al. 2010) e do setor norte da baía do Almirantado - SNBA (ROSA et al. 2014), ambos localizados na Ilha Rei George, constata-se que ocorre heterogeneidade geomorfológica nessas localidades. A Península Keller possui área de 451,5 ha e o SNBA 10.390 ha, e os dois locais possuem características topográficas dispares às encontradas na Península Fildes. A elevação média na Península Fildes é 58,73 m, valor inferior à elevação média da Península Keller (80,3 m) e do SNBA $(299,5 \mathrm{~m})$. Na Península Fildes, $51,4 \%$ de sua superfície está entre 20 e $60 \mathrm{~m}$ de elevação devido ao elevado número de plataformas soerguidas. Na Península Keller, 38,3\% de sua área está posicionada entre as cotas 0 e $50 \mathrm{~m}$, enquanto no SNBA, as superfícies com elevação entre 250 m e 400 m ocupam $41,4 \%$ da área total.

Entre os três locais, o que possui a menor declividade média é o SNBA (12\%), seguido da Península Fildes (15,35\%) e da Península Keller (40,66\%). Contudo, o baixo valor da declividade média do SNBA pode ser influenciado por sua extensa área. Na Península Fildes, as superfícies com declividade entre $3 \%$ e $20 \%$ são predominantes, abrangendo $62,5 \%$ da área total. $\mathrm{Na}$ Península Keller, as declividades hegemônicas variam entre $8 \%$ e 75\%, compreendendo 77,9\% da área total da península. No SNBA o predomínio da declividade ocorre entre $3 \%$ e $45 \%$, referente a $82 \%$ de sua extensão total. Esses valores ratificam que o relevo da Península Fildes é o menos declivoso entre esses três locais na Ilha Rei George.

Em termos percentuais, a única similaridade na orientação das vertentes da Península Fildes e da Península Keller ocorre no predomínio na orientação das vertentes voltadas para oeste. Nos demais sentidos não ocorre similaridade. Esse padrão deve-se principalmente decorrente às diferenças do relevo e a posição das penínsulas na Ilha Rei George.

\section{Considerações finais}

Os métodos empregados nesse estudo possibilitaram caracterizar variáveis morfométricas do relevo da Península Fildes. Utilizando um MDT com resolução espacial de $1 \mathrm{~m}$, foi possível obter com elevado detalhamento as características topográficas do terreno, propiciando inferir acerca das principais geoformas da área de estudo. Os produtos gerados ampliam o banco de dados espaciais da região antártica, podendo servir de base de dados para analises espaciais de outros estudos. Esse estudo contribui para ampliar a compreensão da dinâmica periglacial e mudanças ambientais na Antártica Marítima.

\section{Agradecimentos}

O migrante, intruso meio a mata Amazônica, traz consiOs autores agradecem ao Programa Antártico Brasileiro e à Coordenação de Aperfeiçoamento de Pessoal de Nível Superior (CAPES).

\section{Referências}

ANDRADE, A. M.; ARIGONY-NETO, J.; BREMER, U. F.; MICHEL, R. F. M.; FASSONI-ANDRADE, A. C.; SCHAEFER, C. E. G. R.; SIMÕES, J. C. Cosmo-SkyMed X-band SAR data for classification of ice-free areas and glacier facies on Potter Peninsula, King George Island. Geocarto International. v. 1, p. 1-19, 2015.

ARIGONY-NETO, J.; RAU, F.; SAURER, H.; JAÑA, R.; SIMÕES, J. C.; VOGT, S. A times series of SAR data for monitoring changes in boundaries of glacier zones on the Antarctic Peninsula. Annals of Glaciology. 46. p.55-60, 2007.

BJÖRCK, S.; HÀKANSSON, H.; ZALE, R.; KARLEN, W.; JÖNSSON, B. L. A late Holocene lake sediment sequence from Livingston Island, South Shetland Islands, with palaeoclimatic implications. Antarctic Science. 3(1). p. 61-72, 1991.

BOCKHEIM, J. G.; HALL, K. J. Permafrost, active-layer dynamics and periglacial environments of continental Antarctica. South African Journal of Science. n. 98. p. 8290, 2002.

BURROUGH, P. A.; MCDONNELL, R. A. Principles of Geographical Information Systems. Oxford. 2011. 333 p.

COOPER, A.; MURRAY, R. A structured method of landscape assessment and countryside management. Applied Geography. 12. p. 319-338, 1992.

DIKAU, R. Derivatives from detailed geoscientific maps using computer methods. Zeitschrift Für Geomorphologie. v. 80. p. 45-55, 1990.

EMPRESA BRASILEIRA DE PESQUISA AGROPECUÁRIA EMBRAPA. Serviço Nacional de Levantamento e Conservação de Solos (Rio de Janeiro, RJ). Súmula da 10. Reunião Técnica de Levantamento de Solos. Rio de Janeiro, 1979. 83p. 
ETZELMULLER, B.; SULEBAK, J. R. Developments in the use of digital elevation models in periglacial geomorphology and glaciology. Physische Geographie. v. 41. p. 3558, 2000.

FRANCELINO, M. R.; SCHAEFER, C. E. G. R.; FERNANDES FILHO, E. I.; ALBUQUERQUE FILHO, M. R.; SIMAS, F.N. B.; MOREIRA, G. F. Geoformas da península Keller, Antártica Marítima: subsídios ao monitoramento ambiental. In: SCHAEFER, C. E. G. R.; FRANCELINO, M. R.; SIMAS, F. N. B.; ALBUQUERQUE FILHO, M. R. (Ed). Ecossistemascosteiros e monitoramento ambiental da Antártica marítima: Baía do Almirantado, IIha Rei George. Viçosa: NEPUT. 2004. p. 15-25.

FRENCH, H. M. The Periglacial Environment. $3^{a}$ ed. Otawa: John Wiley \& Sons Ltd. 2007. 480 p.

GROSSE, G.; SCHIRRMEISTER, L.; KUNITSKY, V.V.; HUBBERTEN, H.W. The use of CORONA images in remote sensing of periglacial geomorphology: an illustration from the NE Siberian coast. Permafrost and Periglacial Processes. 16. p.163-172, 2005.

HUTCHINSON, M. F. A new procedure for gridding elevation and stream line data with automatic removal of spurious pits. Journal of Hydrology. 106. p. 211-232, 1989.

IGM; INACH. Carta Topográfica. Instituto Geográfico Militar de Chile e Instituto Antártico Chileno. 1996.

LINDSAY, D. C. Vegetation of the South Shetland Islands. British Antarctic Survey Bulletin. 25. 59-83, 1971.

LÓPES-MARTÍNEZ, J.; SERRANO, E.; SCHMID, T.; MINK, S.; LINÉS, C. Periglacial processes and landforms in the South Shetland Islands (northern Antarctic Peninsula region). Geomorphology. 155-156. p. 62-79, 2012.

MENDES JUNIOR, C. W.; DANI, N.; ARIGONY-NETO, J.; SIMÕES, J. C.; BREMER, U. F.; FONSECA-JÚNIOR, E. S.; ERWES, H. J. B. Análise morfométrica da Península Keller, Antártica, através do SIG. Revista Brasileira de Cartografia. n.62/04, 2010.

MICHEL, R. F. M. Classificação, cobertura vegetal e monitoramento térmico da camada ativa de solos da Península Fildes, Ilha Rei George e Ilha Ardley, Antártica Marítima. 251 f. Tese (Doutorado em Solos e Nutrição de Plantas) - Universidade Federal de Viçosa. 2011.

MICHEL, R. F. M.; SCHAEFER, C. E. G. R.; LÓPEZ-MARTÍNEZ, J.; SIMAS, F. N. B.; HAUS, N. W.; SERRANO, E.; BO-
CKHEIM, J. G. Soils and landforms from Fildes Peninsula and Ardley Island, Maritime Antarctica. Geomorphology. 225. p. 76-86, 2014.

MOORE, I. D.; GRAYSON, R. B.; LADSON, A. R. Digital Terrain Modelling: a review of hydrological, geomorphological, and biological applications. Hydrological Processes. v. 5. p. 3-30, 1991.

MOORE, I. D.; GRAYSON, R. B.; LADSON, A. R. Digital terrain modelling: a review of hydrological, geomorphological, and biological applications. Hydrological Processes. v.5. p. 3-30, 1991.

NAPIERALSKI, J.; HARBOR, J.; LI, Y. Glacial Geomorphology and geographic information systems. Earth-Science Reviews. 85. p. 1-22, 2007.

ØVSTEDAL, D. O.; SMITH, R. I. L. Lichens of Antarctica and South Georgia: A guide to their Identification and Ecology. Cambridge: Cambridge University Press. 2001. $453 \mathrm{p}$.

PETER, H. U.; BUESSER, C.; MUSTAFA, O.; PFEIFFER, S. Risk assessment for the Fildes Peninsula and Ardley Island, and development of management plans for their designation as Specially Protected or Specially Managed Areas. Umweltbundesamt Research Report. 203, 13, 124. UBA-FB 001155e, Texte 20/08. 508 p. 2008.

POELKING, E. L. ; SCHAEFER, C. E. G. R. ; FERNANDES FILHO, E. I. ; ANDRADE, A. M.; SPIELMANN, A. A. Soil-landform-plant-community relationships of a periglacial landscape on Potter Peninsula, maritime Antarctica. Solid Earth. v. 6, p. 583-594, 2015.

ROSA, K. K.; MENDES JÚNIOR, C. W.; VIEIRA, R.; DANI, N.; SIMÕES, J. C. Análise morfométrica do setor norte da baía do Almirantado, Ilha Rei George, Shetlands do Sul, Antártica. Boletim geografia Maringá. v. 32, n. 1. p. 5261, 2014

WEN, J.; KANG, J.; XIE, Z.; HAN, J.; ALBERT, L. Climate, mass balance and glacial changes on small dome of Collins Ice Cap, King George Island, Antarctica. Antarctic Reserch. v.5, n.1, p. 52-61, 1994.

YOON, H. I.; PARK, B. -K.; KIM, Y.; KIM, D. Glaciomarine sedimentation and its paleoceanographic implications along the fjord margins in the South Shetland Islands, Antarctica during the last 6000 years. Palaeogeography, Palaeoclimatology, Palaeoecology. 157. p. 189-211, 2000. 